\title{
UMA NOVA PERSPECTIVA DE PESQUISAS NA ÁREA DE LÍNGUA JAPONESA NO BRASIL: DO PONTO DE VISTA DA LINGÜÍSTICA APLICADA
}

\author{
Yûki Mukai ${ }^{I}$ \\ “(...) não devemos nos afastar das questões práticas só porque \\ a ciência pura soa chique" (RAJAGOPALAN, 2004a, p. 218).
}

RESUMO: Este artigo tem como objetivo considerar a influência da Lingüística Aplicada (LA) em relação à área de língua japonesa (LJ) no Brasil, sistematizar as subáreas e temas abordados nos anais do Encontro Nacional de Professores Universitários de Língua, Literatura e Cultura Japonesa nos sete últimos anos (de 2000 até 2006) na mesma área e identificar aqueles que ainda precisam ser explorados, principalmente, à luz da LA. Primeiramente, abordamos de forma breve o histórico e a natureza de LA (comparada à de Lingüística) no contexto brasileiro, para que, depois, possamos considerar sua influência no âmbito de LJ no Brasil. Nossos levantamentos revelaram que a variedade de subáreas/temas da LA na área de LJ é ainda bastante restrita, e deverá ser desenvolvida de imediato e de forma científico-acadêmica.

Palavras-chave: área de Língua Japonesa no Brasil; Estudos Japoneses no Brasil; Lingüística Aplicada; interdisciplinaridade; transdisciplinaridade.

ABSTRACT: The aim of this paper is to consider the influence of Applied Linguistics (AL) regarding the area of Japanese Language (JL) in Brazil, to classify its subareas and topics approached in the area of $J L$ of the annals of National Meeting of University Professors of Japanese Language, Literature and Culture in the last seven years (2000-2006) and finally, to identify those that are necessary to be explored principally from the point of AL. Firstly, we briefly approached a diachronic matter and the nature of AL (compared to Linguistics) in the Brazilian context in order for us to consider its influence in the area of JL in Brazil. Our analysis revealed that a variety of subareas/topics of $\mathrm{AL}$ in the area of $\mathrm{JL}$ is still restricted and should be immediately developed scientifically and academically.

Key words: area of Japanese Language in Brazil; Japanese Studies in Brazil; Applied Linguistics; interdisciplinary; transdisciplinary.

1. vuki@unb.br Professor efetivo do Curso de Língua e Literatura Japonesa da Universidade de Brasilia (UnB). 


\section{I - Introdução}

Faz apenas três décadas desde quando a Lingüística Aplicada (LA) começou a buscar sua identidade no Brasil. Pode-se dizer que ainda está em busca de sua consolidação e reconhecimento como ciência de linguagem, humana e/ou social. A área de estudos japoneses no Brasil também é relativamente nova, assim como a LA, fato que se constata com a realização do XVIII Encontro Nacional de Professores Universitários de Lingua, Literatura e Cultura Japonesa (ENPULLCJ), realizado na Universidade Estadual Paulista - campus de Assis em 2007, demonstrando o pouco tempo de estudos sobre o tema.

Este artigo tem como objetivo considerar a influência da LA em relação à área de língua japonesa no Brasil, sistematizar as subáreas e temas abordados nos sete últimos anos (de 2000 até 2006) ${ }^{2}$ na mesma área e identificar aqueles que ainda precisam ser explorados, principalmente, à luz da LA.

Nos anais publicados no período supracitado, encontram-se 89 artigos relacionados à língua japonesa e vale ressaltar ainda o fato de que o número de artigos abordados à luz da LA é superior àqueles abordados à luz da Lingüística. Este levantamento demonstra que os estudos de língua japonesa do ponto de vista da LA no Brasil têm crescido bastante e de forma significativa nos últimos anos. No entanto, a variedade de subáreas/temas da LA no âmbito de ensino de língua japonesa é bastante restrita e ainda faltam muitas a serem desenvolvidas.

Dentro desse contexto, nossas perguntas são: quais subáreas/temas de pesquisa devem ser mais exploradas à luz da LA na área de língua japonesa no Brasil e quais podem contribuir para o desenvolvimento e consolidação da mesma área.

Neste trabalho, abordaremos brevemente o histórico e a natureza da LA no Brasil (comparada à da Lingüística) e, depois, como procedimento de pesquisa, levantaremos as subáreas e temas apresentados nos anais do Encontro acima referido desde 2000 até 2006. Este levantamento demonstrará a possibilidade de uma abrangência mais ampla da área de língua japonesa no âmbito da LA, preenchendo assim as lacunas que não têm sido tratadas de forma científicoacadêmica até hoje.

\section{2 - A LA - busca de sua identidade}

Nesta seção, abordaremos de forma breve o histórico (cf. seção 2.1) e a natureza de LA (comparada à de Lingüística) (cf. seção 2.2) no contexto brasileiro, para que, depois, possamos considerar sua influência no âmbito de LJ no Brasil (cf. seção 3).

2. Analisaremos até o ano de 2006, pois até este momento (novembro de 2007), ainda não foram publicados os Anais do ano de 2007. 


\section{1 - O surgimento da LA no Brasil}

É inegável que a LA é uma área nova, pois foi só em 1946 que a LA foi oficialmente reconhecida como disciplina na Universidade de Michigan (cf. Bohn, 1988$, p. 16$)^{3}$.

Aqui no Brasil, por sua vez, foi fundado o primeiro Programa de Estudos Pós-Graduados em Lingüistica Aplicada ao Ensino de Línguas (LAEL) na Pontifícia Universidade Católica de São Paulo, em 1970, e vinte anos após a criação desse programa, foi estabelecida formalmente a Associação de Lingüística Aplicada do Brasil (ALAB), na Universidade Federal de Pernambuco, em julho de 1990 (cf. Celani, 1991, p. 16) ${ }^{4}$.

Segundo Kleiman (1998, p. 52),

a Lingüística Aplicada emergiu um tanto tardiamente em relação ao momento em que se configuraram importantes problemas de ensino de língua materna no país, e foram os lingüistas os que ocuparam os espaços de atuação aplicada que hoje a LA também reivindica (KLEIMAN, 1998, p. 52) (grifo nosso).

Em outras palavras, no Brasil, a LA surgiu primeiramente no interior da Lingüística Estrutural ${ }^{5}$, a fim de resolver problemas práticos sociais de ensino de língua materna (i.e., língua portuguesa) ${ }^{6}$, razão pela qual há pesquisadores que vêem a LA como Lingüística educacional (cf. Spolsky, 1978), Teoria de Ensino de Línguas (cf. Almeida Filho, 1991, p. 8).

A denominação "Lingüística Aplicada" é uma das principais questões epistemológicas da área, como aponta Cavalcanti (1998, p. 209): “a denominação para a área não é adequada porque reduz a LA a uma associação exclusiva à Lingüística, ou seja, à aplicação de teorias lingüísticas. É, no entanto, muito tarde para mudar um nome que está cristalizado"

Nota-se que tanto Kleiman quanto Cavalcanti se referem a uma visão obliqua que existe ainda hoje em relação à LA, isto é, à subordinação à Lingüística e à característica unidirecional da relação lingüística-aplicação. Retomaremos esta

3. Markee (1990, p. 315), por outro lado, aponta que "Howatt (1984) cites the first issue of Language Learning (1948), subtitled A Quarterly Journal of Applied Linguistics, as the first use of this term [Applied Linguistics]". Segundo Almeida Filho (2007, p. 13), “a Universidade de Edimburgo, na Escócia, foi a primeira a criar uma Faculdade de Lingüística Aplicada (School of Applied Linguistics) em 1958"

4. Em relação à fundação da ALAB, Moita Lopes (1996, p. 27-28) ressalta o fato de que "a comunidade nacional de LA sentiu a necessidade da organização política da área, de modo que a voz do lingüista aplicado pudesse ser ouvida pelas agências financiadoras de pesquisa em pé de igualdade com outros grupos de pesquisadores".

5. Cf. Markee (1990, p. 316); Pennycook (1998); Evensen (1998), entre outros. Almeida filho (2007, p. 13), por sua vez, considera que a LA surgiu dentro da lingüística, e também que "foi com o sentido de aplicação de teoria lingüistica que surgiu o termo LA no Brasil nos anos 60".

6. Tanto Celani (1991, p. 17) quanto Almeida Filho (2007, p. 13) consideram que, fora do contexto brasileiro, a noção de Lingüística Aplicada foi interpretada, originalmente, como sinônimo de "ensino/aprendizagem de língua estrangeira". 
questão na seção 2.2 , onde veremos, de modo breve, as características básicas da Lingüística e LA.

\section{2 - Lingüística vs $L A$}

Convém citar aqui a afirmação feita por Celani (1991, p. 21), em relação à natureza das duas disciplinas distintas, i.e., Lingüística e LA:

Por estarem diretamente empenhados na solução de problemas humanos que derivam dos vários usos da linguagem, os lingüistas aplicados estão envolvidos em trabalho que tem uma dimensão essencialmente dinâmica. Os lingüistas, por sua parte, no empenho de resolver problemas lingüisticos, relacionados com algum dos subsistemas da linguagem, que podem ser tornados estáticos, podem encontrar-se isolados das variáveis complexas que afetam o comportamento humano (CELANI, 1991, p. 21) (grifo da autora).

Em outras palavras, a meta do lingüista aplicado é de solucionar problemas reais e práticos relacionados ao uso da linguagem e à interação social pela linguagem, enquanto que a meta do lingüista é primordialmente de descrever uma língua e analisá-la como código lingüístico.

Vejamos, agora, dois tipos de definições de LA, propostos por Markee (1990, p. 315):

Strong definitions of applied linguistics assume that the methods and insights of theoretical linguistics are directly applicable to resolving second language teaching problems. On the other hand, weak definitions do not limit themselves to the resolution of second language teaching problems but potentially address all practical language-related problems (MARKEE, 1990, p. 315) (grifo nosso).

Nota-se que a definição "forte" diz respeito à aplicação de teorias lingüísticas para o ensino de L2, enquanto a definição "fraca", à abordagem "multi-" disciplinar (termo empregado por Markee) para a solução de problemas reais e práticos relacionados à língua(gem). O próprio pesquisador concorda com a definição "fraca" supracitada (como a maioria dos lingüistas aplicados no Brasil), motivado pela falta de flexibilidade da definição "forte" no âmbito de LA e pela dificuldade de aplicar para o ensino de línguas, teorias lingüísticas tais como a gramática gerativa transformacional de Chomsky (Markee, op. cit., p. 318).

Em relação à natureza da LA, Cavalcanti (1998, p. 209), por sua vez, afirma que "é importante enfatizar que a teorização é um componente essencial na pesquisa aplicada", ou seja, a LA é uma área que não apenas aplica teorias lingüísticas como a definição "forte", de Markee, mas também teoriza os resultados adquiridos através de pesquisas aplicadas.

Resumindo a natureza da LA, discutida até agora, a Lingüística não é a única área que contribui para a LA, pois a LA não trabalha apenas com a aplicação de 
teorias lingüísticas, contrariando a posição teórica de Corder $(1974)^{7}$, que ressaltou a unidirecionalidade da relação lingüística-aplicação.

Hoje, a maioria dos lingüistas aplicados brasileiros ${ }^{8}$ (como lingüistas aplicados ocidentais fora do contexto brasileiro) ${ }^{9}$ não concordaria com a visão de que a LAé tutelada, exclusivamente, pela Lingüística, devido às características inter, trans, transgressivas ${ }^{10} \mathrm{e}$ indisciplinares ${ }^{11}$, que têm sido discutidas em relação à natureza de LA.

Vejamos, aqui, apenas os conceitos de inter e transdisciplinaridade de LA, de forma sucinta (por questão de espaço deste trabalho).

Moita Lopes(1996,p. 20-21) faz um levantamento de diversas naturezas de LA, entre elas, uma como a interdisciplinar e mediadora de LA, e afirma: a "LA tem como uma das suas tarefas no percurso de uma investigação mediar entre o conhecimento teórico advindo de várias disciplinas (por exemplo, psicologia, educação, lingüística etc.)"12. Resumindo, a característica interdisciplinar é "empréstimo" de duas ou mais disciplinas, principalmente, da lingüística, psicologia e educação.

O caráter transdisciplinar ${ }^{13}$, por sua vez, é como aquilo que "envolve mais do que a justaposição de ramos do saber [diferentemente da interdisciplinaridade]" (Celani, 1998, p. 132), e "se realiza em uma problemática transversal, através e além e se dissolve em seu objeto segundo Faure (1992)" (apud Celani, 1998, p. 133).

Já Rojo (2006, p. 259) não vê a transdisciplinaridade apenas como a posição teórica de Celani (1998), mas sim defende o caráter transdisciplinar como "leveza de pensamento", pois, para a pesquisadora (2006, p. 254), a LA mais recente "tem buscado e praticado uma 'leveza de pensamento' que a toma capaz, como o xamã, de tentar enfrentar e modificar a precariedade da existência em sociedade ou a privação

7. Lembrando, quanto à postulação teórica de Corder, muitos lingüistas aplicados brasileiros a têm criticado, entre eles, Bohn (1988, p. 10), que afirma que "esta perspectiva [de Corder] transforma a LA numa simples tecnologia, diretamente subordinada aos princípios descritivos da lingüística teórica"

8. Bohn (1988), Celani (1991), Kleiman (1991), Almeida Filho (1991), Moita Lopes (1996), Signorini (1998), Cavalcanti (1998), Rojo (2006), César e Cavalcanti (2007) entre outros.

9. Celani (1991) cita, no seu artigo, Anthony, Buckingham, Campbell, Widdowson, Kaplan, Strevens, Ingram, Crystal entre outros.

10. Termo empregado por Pennycook (2006). Rajagopalan (2004b, p. 410) discute "' 'a necessidade de compreender a LA como um campo de investigação transdisciplinar', o que significa 'atravessar (se necessário, transgredindo) fronteiras disciplinares convencionais com o fim de desenvolver uma nova agenda de pesquisa que, enquanto livremente informada por uma ampla variedade de disciplinas [...]' " (apud Pennycook, 2006, p. 73) (ênfase no original).

11. Termo empregado por Moita Lopes (1998 e 2006). Em conformidade com a visâo de Faure (1992, p. 61) (apud Moita Lopes, 1998, p. 116), Moita Lopes afirma: "as práticas de pesquisa interdisciplinares, por não constituírem disciplinas, constituem, na verdade, Indisciplina [...]"

12. Posteriormente, Moita Lopes (1998, p. 116) critica o caráter interdisciplinar da LA: "uma das criticas que se fazem às tentativas de interdisciplinaridade na produção de conhecimento é a se serem superńciais e desprovidas de critérios de cientificidade".

13. César e Cavalcanti (2007) afirmam: "o termo transculturalidade é considerado mais apropriado para desnaturalizar as questões de hegemonia cultural, sendo o radical trans visto como portador do sentido de movimento multi e bidirecional, e, também, complementar. A noção de transculturalidade aplica-se a uma ampla gama de fenômenos sociais" (grifo das autoras). 
sofrida por sujeitos, comunidades, instituições" Ou seja, o caráter transdisciplinar da LA contemporânea não é apenas transversal, mas sim o de "compreender, interpretar e interferir nas realidades complexas representadas pelas práticas sociais situadas", em conformidade com Rojo (op. cit., p. 259).

Como se viu acima (inclusive as notas de rodapé no. 10 a 13), não existe uma concordância sobre a natureza "adjetivada" da LA, no entanto, como afirma Moita Lopes (2006, p. 41), há um consenso sobre o fato de "a LA estar centrada na produção de conhecimentos relevantes para práticas sociais situadas", o que Rojo (2006, p. 257) chamou de "privações sofridas"

Dentro desse contexto, podemos afirmar que os lingüistas aplicados brasileiros $^{14}$ têm trabalhado até hoje, para liberar epistemológico-metodologicamente a LA da Lingüistica, de forma a buscar sua identidade e autonomia. As características inter, transdisciplinares da LA são o resultado dessa abordagem, da tentativa de se diferenciar e de se justificar perante, principalmente, os lingüistas "puros"15 Ou seja, essas características predominantes da LA são "o resultado do nexo entre a privação social sofrida e a levitação teórica desejada" (Rojo, op. cit., p. 253).

Em relação a uma das preocupações atuais que existe em LA, Pennycook (1998, p. 25), por exemplo, a expõe da seguinte maneira: "um dos maiores problemas que estamos enfrentando é o de que os paradigmas predominantes na Lingüística Aplicada não oferecem o arcabouço teórico para explorar o caráter político da educação de línguas" Resumindo, o teórico refere-se a uma visão de linguagem apolítica e a-histórica, que predomina hoje no âmbito da LA.

Em outro trecho, o mesmo pesquisador (op. cit., p. 29) demonstra sua preocupação em relação a uma ênfase excessiva no ensino de línguas ${ }^{16}$ e na competência comunicativa, afirmando, ainda, que se devem explorar, também, aspectos políticos e culturais da aprendizagem de línguas. Já Moita Lopes (2006, p. 25) aponta esta visão predominante da LA como segue: "ainda entende a LA como área exclusivamente centrada em práticas de ensino/aprendizagem de línguas (sobretudo, estrangeiras), tanto no modo presencial ou à distância, com forte dependência da lingüística"

Dentro desse contexto, é inevitável admitir que a subárea de "ensino/ aprendizagem de línguas" da LA é ainda predominantemente forte, e também que a questão política da educação de línguas é relegada a um plano secundário.

\section{Ver nota 8.}

15. Há crítica em relação à característica de interdisciplinaridade da LA, porque, exatamente devido a sua diversidade desenvolvida até hoje, o foco da LA ficou deslocado. Rampton (2006, p. 121) critica: "os interesses e os focos da LA na área de ensino de línguas são muito amplos, difusos e amorfos, e, no meu ponto de vista, há muita coisa necessitando de reorganização conceitual".

16. Kleiman e Cavalcanti $(2007$, p. 14) apresentam os dados nos quais a maioria dos candidatos (cerca de $70,4 \%$ ) para o curso de pós-graduação do Departamento de Lingüística Aplicada do IEL da Unicamp, no último processo seletivo (ano de 2006), preferiu a área de concentração de "Língua Estrangeira / Segunda Lingua" e "Língua Materna" à área de "Tradução" (cerca de 5,5\%), "Linguagens e Tecnologias" (cerca de 16,5\%) e "Multilingüismo Pluralismo e Educação Bilíngüe" (cerca de 7,3\%) (porcentagem nossa). 


\section{3 - Estudos japoneses no Brasil}

Para verificarmos a influência de LA em relação à área de língua japonesa no Brasil, levantaremos as subáreas e temas ligados à língua japonesa nos anais publicados nos sete últimos anos (de 2000 até 2006) ${ }^{17} \mathrm{O}$ maior objetivo deste levantamento é de identificar aqueles que ainda precisam ser explorados nessa área, principalmente, à luz da LA. Como contextualização, veremos, na seção seguinte, um breve histórico da área de estudos japoneses no Brasil, comparando com o de LA visto nas seções 2.1 e 2.2 .

\section{I - Uma breve visão histórica de estudos japoneses no Brasil}

A época do surgimento e o desenvolvimento tanto da área de LA quanto a de estudos japoneses (doravante EJ) no Brasil são bastante coincidentes.

Quanto à área de língua japonesa (doravante LJ), hoje, sete universidades ${ }^{18}$ oferecem o Curso de Graduação em Letras-Japonês. Entre eles, o mais antigo foi implantado na Universidade de São Paulo (USP), em 1962, e teve o funcionamento efetivo no ano seguinte. No nível de mestrado, o único curso de pós-graduação em língua, literatura e cultura japonesa, no Brasil, foi implantado na USP, em 1995, para ter início de atividades em 1996.

Apesar da coincidência da época do surgimento das duas áreas em questão, podemos observar que há uma diferença nítida entre a área de LA e a de EJ. O curso de pós-graduação em EJ foi implementado apenas há uma década e ainda não está sendo oferecido o mesmo no nível de doutorado no Brasil, podendo-se, então, afirmar que a situação da formação de pesquisadores na área de EJ no Brasil é bem mais precária do que a da LA.

Dentro desse contexto, como uma forma de promover o desenvolvimento da área de estudos japoneses no Brasil, a Fundação Japão em São Paulo ${ }^{19}$ tem patrocinado diversas atividades, entre elas, vale ressaltar aqui duas: a publicação do periódico científico "Estudos Japoneses", promovido pelo Centro de Estudos Japoneses (CEJAP) da USP, cujo primeiro volume foi lançado em 1979; e o encontro anual dos professores universitários da área de língua, literatura e cultura japonesa no Brasil, proposto inicialmente pela mesma instituição, cujo primeiro encontro foi realizado na USP, em 1989.

17. Ver nota 2 e referências bibliográficas.

18. São: Universidade de São Paulo (USP) (Bacharelado, 1962), Universidade Federal do Rio de Janeiro (UFRJ) (Bacharelado e Licenciatura, 1979), Universidade Federal do Rio Grande do Sul (UFRGS) (Bacharelado, 1986), Universidade Estadual Paulista (UNESP) - Campus de Assis (Licenciatura, 1992), Fundação Universidade de Brasília (UnB) (Licenciatura, 1997), Universidade Estadual do Rio de Janeiro (UERJ) (Licenciatura, 2004) e Universidade Federal do Paraná (UFPR) (Bacharelado e Licenciatura, 2008).

19. A Fundação Japão foi constituída legalmente em 1972 no Japão. 


\section{2 - Levantamento das subáreas e temas na área de língua japonesa}

Com o intuito de considerarmos a influência de $\mathrm{LA}$ em relação à área de $\mathrm{LJ}$ no Brasil, fizemos o levantamento das subáreas e temas abordados no âmbito de LJ dos anais publicados nos sete últimos anos (de 2000 até 2006).

Nos anais publicados no período acima referido, encontram-se 89 artigos relacionados à LJ. Observa-se que, de 89 , encontram-se 48 em LA e 41 em Lingüística (cf. quadro 1). Vale ressaltar, ainda, o fato de que o número dos artigos abordados à luz da LA é superior àqueles abordados à luz da Lingüística, de 2003 até os dias de hoje (cf. quadro 1).

QUADRO 1: NÚMERO TOTAL DE ARTIGOS PUBLICADOS E ABORDADOS Á LUZ DA LINGÜÍSTICA E DA LINGÜÍSTICA APLICADA NOS ANAIS DO ENPULLCJ, NO PERÍODO DE 2000 A 2006

\begin{tabular}{|c|c|c|c|}
\hline Nome do Encontro/Congresso & $\begin{array}{l}\text { No. de artigos } \\
\text { abordados à luz } \\
\text { da Lingitisticd }\end{array}$ & $\begin{array}{c}\text { No. de artigos } \\
\text { abordados à } \\
\text { luz da } \\
\text { LA }\end{array}$ & $\begin{array}{c}\text { No. total } \\
\text { de artigos } \\
\text { relacionados } \\
\text { à LJ }\end{array}$ \\
\hline $\begin{array}{l}\text { XI ENPULLCJ - } \\
\text { I Encontro de Estudos } \\
\text { Japoneses (2000) }\end{array}$ & 6 & 4 & 10 \\
\hline $\begin{array}{l}\text { XII ENPULLCJ- } \\
\text { II Encontro de Estudos } \\
\text { Japoneses (2001) }\end{array}$ & 6 & 6 & 12 \\
\hline XIII ENPULLCJ (2002) & 7 & 4 & 11 \\
\hline XIV ENPULLCJ (2003) & (7. & 8 & 15 \\
\hline XV ENPULLCJ (2004) & 8 & i11. & 19 \\
\hline $\begin{array}{l}\text { XVI ENPULLCJ - } \\
\text { III Congresso Internacional de } \\
\text { Estudos Japoneses no Brasil } \\
(2005)\end{array}$ & 3. & 8 & 11 \\
\hline $\begin{array}{l}\text { XVII ENPULLCJ - } \\
\text { IV Congresso Internacional de } \\
\text { Estudos Japoneses no Brasil } \\
\text { (2006) }\end{array}$ & 4. & 7 & 11 \\
\hline Total & 41 & 48 & 89 \\
\hline
\end{tabular}


Os resultados acima demonstram que a filiação dos pesquisadores de $\mathrm{LJ}$ no Brasil tem mudado da Lingüística para a LA nos últimos anos, podendo-se afirmar, então, que o interesse pela LA tem aumentado de forma significativa no âmbito de LJ no Brasil.

Vejamos, agora, as subáreas da LA cujos artigos estão relacionados à LJ. QUADRO 2: SUBÁREAS/TEMAS DA LA NO ÂMBITO DA LÍNGUA JAPONESA,
NOS ANAIS DO ENPULLCJ, NO PERÍODO DE 2000 A 2006

\begin{tabular}{|c|c|c|c|c|}
\hline & Subáreas & Temas & $\begin{array}{l}\text { No. de } \\
\text { artigos }\end{array}$ & Subtotal \\
\hline \multirow[t]{12}{*}{2.1} & \multirow[t]{12}{*}{ Ensino de LE } & Ensino de LE (geral) & 1 & \multirow{12}{*}{31} \\
\hline & & $\begin{array}{l}\text { Ensino de LE (Expressão } \\
\text { idiomática) }\end{array}$ & 1 & \\
\hline & & Ensino-aprendizagem de $L E / L 2^{20}$ & 5. & \\
\hline & & Gramática pedagógica & 10 & \\
\hline & & Escrita & 1 & \\
\hline & & Fonética e fonologia & 1 & \\
\hline & & Material didático - impresso & 2 & \\
\hline & & Material didático-multimidia & 5. & \\
\hline & & Metodologia & 1 & \\
\hline & & Avaliação pelos professores & 2 & \\
\hline & & Motivação do aprendizado & 1 & \\
\hline & & Formação de professores & 1 & \\
\hline 2.2 & Tradução & Tradução & 3 & 3 \\
\hline 2.3 & Terminologia & Terminologia & 4 & 4 \\
\hline \multirow[t]{3}{*}{2.4} & Bilingüismo & Bilingüismo & 2 & \multirow[b]{3}{*}{4} \\
\hline & & Identidade & 1 & \\
\hline & & Interculturalidade & 1 & \\
\hline 2.5 & $\begin{array}{l}\text { Língua, } \\
\text { Linguagem e } \\
\text { Informação }\end{array}$ & $\begin{array}{l}\text { Língua, cultura e transferência de } \\
\text { informação }\end{array}$ & 1 & 1 \\
\hline 2.6 & LIBRAS & LIBRAS & 1 & 1 \\
\hline \multirow[t]{4}{*}{2.7} & \multirow[t]{4}{*}{ Análise } & Análise de erros & 1 & \multirow[b]{4}{*}{4} \\
\hline & & Análise de material didático & 1 & \\
\hline & & Análise de conversação & 1 & \\
\hline & & $\begin{array}{l}\text { Análise do curso de língua } \\
\text { japonesa }\end{array}$ & 1 & \\
\hline & & & Total & 48 \\
\hline
\end{tabular}

20. Nos Estudos da Aquisição-Aprendizagem de Línguas Estrangeiras, as noçôes LE e L2 diferenciam-se com base no contexto onde se aprende uma língua estrangeira: caso se aprenda o inglês, por exemplo, nos países ou comunidade em que se fala/utiliza essa mesma língua como meio de comunicação, considera-a como segunda língua (L2); caso se aprenda o inglês nos países ou comunidade em que não se fala/utiliza essa mesma língua como meio de comunicação, considera-a como língua estrangeira (LE). 
Observa-se que a subárea de "Ensino de LE" (cf. item 2.1, do quadro 2) é predominante em relação às outras subáreas, ocupando $64,6 \%$ do total. Dentro dessa subárea, percebe-se, ainda, que são prevalecentes os três temas a seguir: gramática pedagógica, ensino-aprendizagem de LE/L2, material didático - multimídia, ocupando $20,8 \%, 10,4 \%$ e $10,4 \%$ do total, respectivamente.

Considerando todas as subáreas vistas no quadro acima, de forma geral, parece que há diversidade das mesmas, porém, como já foi mencionado no parágrafo anterior, a subárea de "Ensino de LE" tem sido focalizada de forma predominante, podendo-se ressaltar o fato de que, nos sete últimos anos (de 2000 a 2006), não têm sido desenvolvidas as outras subáreas da LA no âmbito da área de LJ no Brasil.

Lembramos que, na seção 2.2, referimo-nos à preocupação de Pennycook (1998) e Moita Lopes (2006), em relação a uma ênfase excessiva no ensino de línguas, dada no âmbito da LA. Observa-se que essa tendência predominante é vista, também, na área de LJ no Brasil, como demonstra o resultado do quadro 2.

Com o intuito de detectarmos as outras subáreas a serem desenvolvidas de forma científica, comparamos as subáreas no quadro $2 \mathrm{com}$ aquelas que foram apresentadas no site ${ }^{21}$ do VIII Congresso Brasileiro de Lingüística Aplicada (CBLA), organizada pela Associação de Lingüística Aplicada do Brasil (ALAB), realizado na UnB, no período de 9 a 11 de julho de 2007. Pelo site, os temas estão agrupados como demonstra o quadro 3 .

\section{QUADRO 3: AGRUPAMENTO DE TEMAS DE LA PELO SITE DO VIII CBLA}

\begin{tabular}{|c|c|}
\hline 1. Politicas Linguísticas & $\begin{array}{l}\text { 8. Relaçóes sociais mediadas pela } \\
\text { linguagem }\end{array}$ \\
\hline $\begin{array}{l}\text { 2. Disciplinaridade da Lingüística } \\
\text { Aplicada }\end{array}$ & 9. Traducão \\
\hline 3. Ensino de língua materna & $\begin{array}{l}\text { 10. Contextos bilinguies e língua } \\
\text { segunda de fronteira }\end{array}$ \\
\hline 4. Português LE & $\begin{array}{l}\text { 11. Ensino de LIBRAS e formação de } \\
\text { professores }\end{array}$ \\
\hline 5. Formacâo de professores & 12. Educação inclusiva \\
\hline $\begin{array}{l}\text { 6. O Ensino de línguas e as Novas } \\
\text { tecnologias }\end{array}$ & $\begin{array}{l}\text { 13. Línguas indígenas (ensino/ } \\
\text { aprendizagem e formação de } \\
\text { professores indígenas) }\end{array}$ \\
\hline 7. Terminologia Aplicada e Lexicografia & 14. Ensino a distância \\
\hline
\end{tabular}

(enumeração e grifo nossos)

21. <http://www.alab.org.br $>$ Acesso em 10 de maio de 2007. 
Os resultados do quadro 2 e do agrupamento dos temas acima apresentados nos revelaram que os temas que estão em negrito (cf. quadro 3) têm a necessidade de serem abordados e desenvolvidos, de forma científico-acadêmica, na área de $\mathrm{LJ}$ no Brasil.

\section{- Políticas Lingüísticas}

Para que nossa área de LJ possa se tornar mais consolidada e reconhecida no Brasil, precisamos abordar e ponderá-la do ponto vista mais político. Ou seja, para o desenvolvimento da área, devemos discutir e argumentar mais sobre a consolidação e fortalecimento da área no nível institucional e/ou governamental.

\section{- Formação de professores (de LJ)}

Apesar de ter crescido a formação de pesquisadores (mestres) na área de LJ no Brasil, isso não significa que tem aumentado o número de professores de LJ de alta qualidade, pois a palavra "pesquisador" não é sinônimo de "professor de língua" Dentro desse contexto, é indispensável a realização de um treinamento de professores não apenas para formandos, mas também para aqueles que já atuam no ensino de LJ. Precisa-se, também, da pesquisa metodológico-acadêmica voltada para este tema, para que se possa detectar o que ainda falta na teorização e na aplicação de formação de professores de LJ.

\section{- Relações sociais mediadas pela linguagem e Contextos bilíngües}

A pesquisa sobre a língua em si é indubitavelmente importante para elucidar o sistema lingüístico de uma língua natural. Entretanto, a língua não existe por si só, mas sim porque existem o contexto e os usuários da mesma. Levando isso em consideração, precisa-se, também, das pesquisas que tratam dos fatores extralingüísticos, principalmente, dos político-sociais, tais como o contexto escolar, institucional, empresarial, familiar e bilíngüe, a hierarquia, a idade, o sexo, a L1/L2 dos falantes inclusive os imigrantes e seus descendentes.

\section{- Tradução}

Como demonstra o quadro 2, esta subárea é ainda pouco desenvolvida e tratada de forma metodológico-científica na área de $\mathrm{LJ}$ no Brasil. A tradução não se refere apenas à tradução literária e técnica, ou seja, ao produto propriamente dito, mas também à parte teórica e processo tradutório, ao ensino de tradução, e à aplicação de tradução no ensino de línguas.

\section{- Ensino a distância}

O desenvolvimento e a utilização/aplicação da tecnologia, principalmente, da internet facilitaram não apenas a comunicação em geral, mas também o ensino a distância. Entretanto, na área de LJ no Brasil, ainda não foi apresentado nenhum 
trabalho científico-acadêmico sobre ensino a distância (cf. quadro 2), tornando-se, então, uma das subáreas mais precárias, ou seja, menos desenvolvidas na área de LJ. Portanto, são necessárias, com urgência, as pesquisas que envolvem a abordagem metodológica e científico-acadêmica, e a aplicação do ensino a distância na área de LJ.

\section{Considerações finais}

Neste artigo, primeiramente, abordamos de forma breve o histórico e a natureza de LA (comparada à de Lingüística) no contexto brasileiro, para que, depois, possamos considerar sua influência no âmbito de LJ no Brasil.

Vimos que a LA é uma área relativamente nova como a de EJ no Brasil, e os lingüistas aplicados brasileiros (como a maioria dos lingüistas aplicados ocidentais fora do Brasil) (ver notas 8 e 9) têm trabalhado para liberar epistemológicometodologicamente a LA da Lingǘstica, de forma a buscar sua identidade e autonomia como ciência de linguagem, humana e/ou social (cf. seções 2.1 e 2.2). Hoje, podemos afirmar, então, que a LA já não é mais subordinada à Lingüística, devido a suas características, principalmente, inter e transdisciplinares (cf. seção 2.2), ou seja, essas características predominantes da LA contemporânea são o resultado da "leveza de pensamento", designada por Rojo (2006, p. 254) (cf. seção 2.2).

Depois de considerarmos a natureza da Lingüística e LA, com o intuito de verificarmos a influência da LA na área de LJ no Brasil, fizemos o levantamento das subáreas e temas abordados no âmbito de LJ dos anais (ENPULLCJ) publicados nos sete últimos anos (de 2000 até 2006), e procuramos identificar aqueles que ainda precisam ser explorados na área de LJ, principalmente, à luz da LA (cf. seção 3.2).

Vale ressaltar o fato de que o número dos artigos abordados à luz da LA é superior àqueles abordados à luz da Lingüística a partir de 2003 (cf. quadro 1 da seção 3.2), podendo-se afirmar, então, que a área de LJ no âmbito da LA no Brasil tem crescido bastante e de forma significativa nos últimos anos.

No entanto, como foi verificado no quadro 2 , a variedade de subáreas/temas da LA na área de LJ é ainda bastante restrita, e nossos levantamentos e resultados (cf. quadros 2 e 3) demonstraram que, nessa área, deverão ser desenvolvidas de imediato e de forma científico-acadêmica, as subáreas/temas a seguir: políticas lingüísticas, formação de professores, relações sociais mediadas pela linguagem, tradução, contextos bilíngües e ensino a distância.

Este trabalho preliminar do ponto de vista da LA na área de LJ no Brasil estimulará e contribuirá, de forma modesta, não apenas para a mudança de consciência dos pesquisadores na mesma área, mas também para seu desenvolvimento, consolidação e reconhecimento no Brasil. 


\section{Referências Bibliográficas}

ALMEIDA FILHO, J. C. P. Maneiras de compreender Lingüística Aplicada. Letras, vol. 02, Santa Maria: Editora da UFSM, p. 7-15, jul./dez. 1991.

. Lingüística Aplicada: Ensino de línguas e comunicação. 2. ed. Campinas-SP: Pontes Editores e ArteLíngua, 2007.

ASSOCIAÇÃO DE LINGÜÍSTICA APLICADA DO BRASIL (org.) Temas de Lingüística Aplicada. <http:/www.alab.org.br> Acesso em 10 de maio de 2007.

BOHN, H. I. Lingüística Aplicada. In: BOHN, H. I.; VANDRESEN, P. (orgs.). Tópicos de Lingǘstica Aplicada. Editora da Universidade Federal de Santa Catarina, 1988, p. 11-39.

CAVALCANTI, M. C. AILA. 1996 e um estado da arte em microcosmo da Lingüística Aplicada. In: SIGNORINI, I. e CAVALCANTI M. C. (orgs.). Lingüística Aplicada e Transdisciplinaridade. 1. ed. Campinas - SP: Mercado de Letras, 1998, p. 81-98.

CELANI, M. A. A. Afinal, o que é Lingüística Aplicada? In: ZANOTTO P. M. S.; CELANI, M. A. A. (orgs.). A Linguística Aplicada: da aplicação da Lingüística à Lingüística transdisciplinar. São Paulo: Educ., 1991, p. 15-23.

Transdisciplinaridade na Lingǘstica Aplicada no Brasil. In: SIGNORINI, I. e CAVALCANTI M. C. (orgs.). Linguíística Aplicada e Transdisciplinaridade. 1. ed. Campinas - SP: Mercado de Letras, 1998, p. 129-142.

CÉSAR, A. L.; CAVALCANTI, M. C. Do singular para o multifacetado: o conceito de língua como caleidoscópio. In: CAVALCANTI, M. C.; BORTONI-RICARDO, S. M. (orgs.). Transculturalidade, linguagem e educação. 1. ed., Campinas-SP: Mercado de Letras, 2007, p. 45-66.

CORDER, S. P. The significance of learners' errors. In: RICHARDS, J. C. Error Analysis: Perspectives on Second Language Acquisition. 1. ed. Essex: Longman, 1974, p. 19-54.

EVENSEN, L. S. A Lingüística Aplicada a partir de um arcabouço com princípios caracterizadores de disciplinas e transdisciplinas. Trad. de Maria da Glória de Moraes. In: SIGNORINI, I. e CAVALCANTI M. C. (orgs.). Linguíística Aplicada e Transdisciplinaridade. 1. ed. Campinas - SP: Mercado de Letras, 1998, p. 81-98.

FAURE, G. O. A constituição da interdisciplinaridade: Barreiras institucionais e intelectuais. Revista Tempo Brasileiro 108, p. 61-68, 1992.

FUNDAÇÃO JAPÃO (org.). Ensino de língua japonesa: escolas e cursos. São Paulo: Centro de Língua Japonesa da Fundação Japão em São Paulo, 2003.

HOWATT, A. P. R. A History of English Language Teaching. Oxford: Oxford University Press, 1984. 
KLEIMAN, A. B. O ensino de línguas no Brasil. In: ZANOTTO P. M. S.; CELANI, M. A. A. (orgs.). A Lingüística Aplicada: da aplicação da Lingüística à Lingüística transdisciplinar. 1. ed. São Paulo: Educ., 1991, p. 25-36.

- O estatuto disciplinar da Lingüística Aplicada: o traçado de um percurso, um rumo para o debate. In: SIGNORINI, I. e CAVALCANTI M. C. (orgs.). Lingüística Aplicada e Transdisciplinaridade. 1. ed. Campinas - SP: Mercado de Letras, 1998, p. 51-77.

KLEIMAN, A. B.; CAVALCANTI, M. C. O DLA: uma história de muitas faces, um mosaico de muitas histórias. In: KLEIMAN, A. B.; CAVALCANTI, M. C. (orgs.). Lingüística Aplicada: suas faces interfaces. 1. ed., Campinas-SP: Mercado de Letras, 2007, p. 9-23.

MARKEE, N. Applied Linguistics: what's that? System, vol. 18, no.3, p. 315-323, 1990.

MOITA LOPES, L. P. da. Oficina de Lingüística Aplicada: a natureza social e educacional dos processos de ensino/aprendizagem de línguas. 5. reimpressão. CampinasSP: Mercado de Letras Edições e Livraria Ltda., 2003 (1. ed., 1996).

A transdisciplinaridade é possível em Lingüística Aplicada? In: SIGNORINI, I. e CAVALCANTI M. C. (orgs.). Lingüística Aplicada e Transdisciplinaridade. 1. ed. Campinas - SP: Mercado de Letras, 1998, p. 113-128.

. Uma Lingüística Aplicada mestiça e ideológica: interrogando o campo como lingüista aplicado. In: MOITA LOPES, L. P. da (org.). Por uma Lingüística Aplicada indisciplinar. 1. ed. São Paulo: Parábola Editorial, 2006, p.13-44.

PENNYCOOK, A. A Lingüística Aplicada dos anos 90: em defesa de uma abordagem crítica. Trad. de Denise B. Braga e Maria Cecília dos Santos F. In: SIGNORINI, I. e CAVALCANTI M. C. (orgs.). Lingüística Aplicada e Transdisciplinaridade. 1. ed. Campinas - SP: Mercado de Letras, 1998, p. 23-49.

. Uma Lingüística Aplicada transgressiva. In: MOITA LOPES, L. P. da (org.). Por uma Lingüística Aplicada indisciplinar. 1. ed. São Paulo: Parábola Editorial, 2006, p.67-84.

RAJAGOPALAN, K. Línguas nacionais como bandeiras patrióticas, ou a Lingüística que nos deixou na mão. In: SILVA, F. L. da e RAJAGOPALAN, K. (orgs.). A lingüística que nos faz falhar: investigação crítica. 1. ed. São Paulo: Parábola Editorial, 2004a, p. 11-38.

Resposta aos meus debatedores. In: SILVA, F. L. da e RAJAGOPALAN, K. (orgs.). A lingüística que nos faz falhar: investigação crítica. 1. ed. São Paulo: Parábola Editorial, 2004a, p. 166-231.

The Philosophy of Applied Linguistics. In: DAVIES, A.; ELDER, C. (orgs.). The Handbook of Applied Linguistics. 1. ed. Oxford: Blackwell Publishing Ltd., 2004b, p. 397-420. 
RAMPTON, B. Continuidade e mudança nas visões de sociedade em Lingüística Aplicada. In: SILVA, F. L. da e RAJAGOPALAN, K. (orgs.). A lingüística que nos faz falhar: investigação crítica. 1. ed. São Paulo: Parábola Editorial, 2004, p. 109-128.

ROJO, R. H. R. Fazer Lingüística Aplicada em perspectiva sócio-histórica: privação sofrida e leveza de pensamento. In: MOITA LOPES, L. P. da (org.). Por uma Lingüística Aplicada indisciplinar. 1. ed. São Paulo: Parábola Editorial, 2006, p.253-276.

SIGNORINI, I. Do residual ao múltiplo e ao complexo: o objeto da pesquisa em Lingüística Aplicada. In: SIGNORINI, I. e CAVALCANTI M. C. (orgs.). Lingüística Aplicada e Transdisciplinaridade. 1. ed. Campinas - SP: Mercado de Letras, 1998, p. 81-98.

SPOLSKY, B. Educational Linguistics. Rowley, MA: Newbury House, 1978.

\section{Anais Analisados (ordem cronológica):}

ENCONTRO NACIONAL DE PROFESSORES UNIVERSITÁRIOS DE LÍNGUA, LITERATURA E CULTURA JAPONESA, 11., ENCONTRO DE ESTUDOS JAPONESES, 1., 2000, Brasília. Anais... Brasília: Universidade de Brasília. Instituto de Letras. Departamento de Línguas Estrangeiras e Tradução, 2001.

ENCONTRO NACIONAL DE PROFESSORES UNIVERSITÁRIOS DE LÍNGUA, LITERATURA E CULTURA JAPONESA, 12., ENCONTRO DE ESTUDOS JAPONESES, 2., 2001, Porto Alegre. Anais... Porto Alegre: Universidade Federal do Rio Grande do Sul. Setor de Japonês/Núcleo de Estudos Japoneses, 2001.

ENCONTRO NACIONAL DE PROFESSORES UNIVERSITÁRIOS DE LÍNGUA, LITERATURA E CULTURA JAPONESA, 13., 2002, São Paulo. Anais... São Paulo: Universidade de São Paulo. Faculdade de Filosofia, Letras e Ciências Humanas. Centro de Estudos Japoneses da USP, 2003.

ENCONTRO NACIONAL DE PROFESSORES UNIVERSITÁRIOS DE LÍNGUA, LITERATURA E CULTURA JAPONESA, 14., 2003, Assis-SP. Anais... Assis-SP: Universidade Estadual Paulista. Faculdade de Ciências e Letras, 2003.

ENCONTRO NACIONAL DE PROFESSORES UNIVERSITÁRIOS DE LÍNGUA, LITERATURA E CULTURA JAPONESA, 15., 2004, Rio de Janeiro. Anais... Rio de Janeiro: Universidade Federal do Rio de Janeiro. Faculdade de Letras, Departamento de Letras orientais e eslavas. Setor de Letras Japonesas, 2004.

CONGRESSO INTERNACIONAL DE ESTUDOS JAPONESES NO BRASIL, 3., ENCONTRO NACIONAL DE PROFESSORES UNIVERSITÁRIOS DE LÍNGUA, LITERATURA E CULTURA JAPONESA, 16., 2005, Brasília. Anais... Brasília: Universidade de Brasília. Instituto de Letras. Departamento de Línguas Estrangeiras e Tradução, 2006. 
ENCONTRO NACIONAL DE PROFESSORES UNIVERSITÁRIOS DE LÍNGUA, LITERATURA E CULTURA JAPONESA, 17., CONGRESSO INTERNACIONAL DE ESTUDOS JAPONESES NO BRASIL, 4., 2006, São Paulo. Anais... São Paulo: Universidade de São Paulo. Faculdade de Filosofia, Letras e Ciências Humanas. Centro de Estudos Japoneses, 2007. 